\title{
Schistosome tegumental ecto-apyrase (SmATPDase1) degrades exogenous pro-inflammatory and pro-thrombotic nucleotides
}

Schistosomes are parasitic worms that can survive in the hostile environment of the human bloodstream where they appear refractory to both immune elimination and thrombus formation. We hypothesize that parasite migration in the bloodstream can stress the vascular endothelium causing this tissue to release chemicals alerting responsive host cells to the stress. Such chemicals are called damage associated molecular patterns (DAMPs) and among the most potent is the proinflammatory mediator, adenosine triphosphate (ATP). Furthermore, the ATP derivative ADP is a pro-thrombotic molecule that acts as a strong activator of platelets. Schistosomes are reported to possess at their host interactive tegumental surface a series of enzymes that could, like their homologs in mammals, degrade extracellular ATP and ADP. These are alkaline phosphatase (SmAP), phosphodiesterase (SmNPP-5) and ATP diphosphohydrolase (SmATPDase1). In this work we employ RNAi to knock down expression of the genes encoding these enzymes in the intravascular life stages of the parasite. We then compare the abilities of these parasites to degrade exogenously added ATP and ADP. . We find that only SmATPDase1-suppressed parasites are significantly impaired in their ability to degrade these nucleotides. Suppression of SmAP or SmNPP-5 does not appreciably affect the worms' ability to catabolize ATP or ADP. These findings are confirmed by the functional characterization of the enzymatically active, fulllength recombinant SmATPDase1 expressed in CHO-S cells. The enzyme is a true apyrase; SmATPDase1 degrades ATP and ADP in a cation dependent manner. Optimal activity is seen at alkaline $\mathrm{pH}$. The $\mathrm{K}_{\mathrm{m}}$ of SmATPDase 1 for ATP is $0.4 \pm 0.02 \mathrm{mM}$ and for ADP, $0.252 \pm$ $0.02 \mathrm{mM}$. The results confirm the role of tegumental SmATPDase1 in the degradation of the exogenous pro-inflammatory and pro-thrombotic nucleotides ATP and ADP by live intravascular stages of the parasite. By degrading host inflammatory signals like ATP, and pro-thrombotic signals like ADP, these parasite enzymes may minimize host immune 
responses, inhibit blood coagulation and promote schistosome survival. 
2 Akram A. Da'dara, Rita Bhardwaj, Yasser BM Ali*, Patrick J. Skelly.

3 Molecular Helminthology Laboratory, Department of Infectious Disease

4 and Global Health, Cummings School of Veterinary Medicine, Tufts

5 University, North Grafton, MA, USA

6 Corresponding author: Patrick Skelly, Molecular Helminthology

7 Laboratory, Department of Infectious Disease and Global Health,

8 Cummings School of Veterinary Medicine, Tufts University, North

9 Grafton, MA, USA. Phone: 508-887-4348; Email:

10 Patrick.Skelly@Tufts.edu

11 *Current address: Genetic Engineering and Biotechnology Research

12 Institute, Sadat City University, Egypt. 
Schistosomes are intravascular worms, commonly known as blood flukes that cause the debilitating disease schistosomiasis. Over 200 million people are estimated to be infected with these worms globally and more than 600 million live at risk of infection (Vennervald \& Dunne 2004). Disease caused by Schistosoma mansoni is characterized clinically by abdominal pain, diarrhea, portal hypertension, anemia and chronic hepatic and intestinal fibrosis (Gryseels et al. 2006).

Mature male schistosomes are approximately $10 \mathrm{~mm}$ long and possess a ventral groove called the gynaecophoric canal in which the longer, cylindrical adult female often resides. In cross section, the male/female pair spans about $1 \mathrm{~mm}$. Both sexes possess a pair of suckers (an anterior oral sucker and a ventral sucker) that are used for attachment to the blood vessel lining and to facilitate intravascular movement (Hockley \& McLaren 1973). Large tubercles are present on the dorsal surface of male $S$. mansoni, posterior to the ventral sucker. Tubercles are studded with prominent, rigid spines composed of actin bundles (Cohen et al. 1982). Female worms possess relatively few spines and their surface, while smoother and lacking large tubercles, is otherwise similar to the pitted and ridged surface of the male (Senft et al. 1961; Silk et al. 1969).

S. mansoni adult worms wander extensively within the complex venous system draining the intestinal tract (Pellegrino \& Coelho 1978). Both single and paired worms move constantly along the vessels (Bloch 1980). The relatively large adults enter blood vessels whose diameter is equivalent to their own (Bloch 1980). In addition, the worms can elongate considerably to enter even smaller vessels, such as the mesenteric venules, to lay eggs (Bloch 1980).

Parasite suckers, tubercles and spines used for migration in the bloodstream can impinge on host

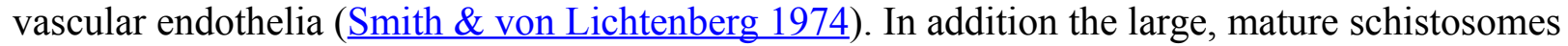
moving through small blood vessels hamper and alter blood flow (Bloch 1980), almost certainly causing sheer stress and restricting local $\mathrm{O}_{2}$ concentration. All of these conditions, leading to endothelial cell stress, may trigger the release by these cells of endogenous distress signals. These signals, known collectively as damage-associated molecular patterns (DAMPs), indicate tissue damage to the host and can initiate primary immune responses. Extracellular nucleotides such as ATP are known to function as potent DAMPs by acting as endogenous tissue-derived signaling molecules that contribute to inflammation and immunity. Following tissue damage or during inflammation, or when exposed to shear stress, many cells release ATP (Hanley et al. 2004; Lohman et al. 2012). There is a substantial literature demonstrating that extracellular ATP can function as a proinflammatory immunomediator by acting on multiple immunological effector cell types including neutrophils, macrophages, dendritic cells, and lymphocytes (Reviewed in (Bours et al. 2006; Hanley et al. 2004; Yegutkin 2008).

General activation of the immune system following exposure to DAMPs can be controlled by their degradation in a timely manner. For instance, concentrations of ATP in the extracellular compartments of vertebrates are regulated by the following membrane-bound, nucleotidemetabolizing ecto-enzymes: alkaline phosphatase, phosphodiesterase and ATPdiphosphohydrolase (Bours et al. 2006; Burnstock 2006). ATP degradation in this manner helps prevent uncontrolled inflammation and averts collateral cell damage.

As noted, schistosomes in the vasculature may directly and indirectly stress the endothelium which could lead to the release of the DAMP, ATP (Bhardwaj \& Skelly 2009). This would then 
stimulate inflammatory immune responses in the vicinity of the worms that could debilitate and kill them. However, it has been shown that schistosomes, like their hosts, express a panel of ectoenzymes that could catabolize ATP. These are alkaline phosphatase (SmAP), phosphodiesterase (SmNPP-5) and ATP-diphosphohydrolase (SmATPDase1) (Bhardwaj \& Skelly 2009). We hypothesize that these parasite tegumental enzymes specifically counteract ATP DAMP-mediated inflammatory signaling and limit the host's attempts to focus inflammatory mediators around the worms (Bhardwaj \& Skelly 2009). In this manner, these tegumental molecules help impair host immune defenses and promote parasite survival.

In addition to contending with host immunity, intravascular schistosomes, which act as obstructions in the blood vessels, also need adaptations to avoid promoting blood coagulation in their vicinity. The ectoenzymes under study here may exert a key regulatory influence on these processes too. Platelets play a central role in blood clotting and ATP can regulate platelet reactivity by way of direct action on platelet purinergic receptors (Mahaut-Smith et al. 2000). In addition, the first step in ATP hydrolysis leads to the generation of ADP and ADP is a major agonist of platelet recruitment and aggregation (Gachet 2006). Furthermore, platelets themselves can damage schistosomes (Joseph et al. 1983). Therefore the catabolism of ATP and ADP via SmAP, SmNPP-5 and/or SmATPDase1 may additionally lead to the inhibition of platelet aggregation and thrombus formation around the worms.

It has long been known that schistosome tegumental extracts do possess ATP and ADP hydrolyzing activity (Vasconcelos et al. 1993). Electron microscopy analysis identified electrondense lead phosphate deposits on the outer surface of adult parasites upon hydrolysis of ATP or ADP and the production of inorganic phosphate (Vasconcelos et al. 1996; Vasconcelos et al. 1993). These data suggest that the activity is external to the body of the worm but do not identify the enzyme(s) responsible. One candidate is schistosome alkaline phosphatase (SmAP). The cDNA encoding SmAP was recently cloned and characterized (Bhardwaj \& Skelly 2011). SmAP is a $\sim 62 \mathrm{kDa}$ glycosylphosphatidylinositol (GPI) anchored protein that is expressed in the tegument and internal tissues of the adult worms (Bhardwaj \& Skelly 2011; Cesari 1974; Dusanic 1959; Levi-Schaffer et al. 1984; Morris \& Threadgold 1968; Pujol et al. 1990). The protein can be cleaved from cultured schistosomula (Espinoza et al. 1988) and from adult worms (CastroBorges et al. 2011) by the phosphatidylinositol-cleaving enzyme - phosphatidylinositol-specific phospholipase C. Tegumental proteomic analysis confirms that SmAP is found in the schistosome surface membranes (Braschi et al. 2006; van Balkom et al. 2005) and is available for surface biotinylation (Braschi \& Wilson 2006).

Proteomic analysis of tegument preparations revealed a second potential ATP and ADP hydrolyzing enzyme there, specifically a phosphodiesterase designated SmNPP-5 that could also be biotinylated at the adult parasite surface (Braschi et al. 2006; Braschi \& Wilson 2006). SmNPP-5 is a $\sim 53 \mathrm{kDa}$ protein possessing a single C-terminal transmembrane domain that is expressed exclusively in the intra-mammalian life stages (Rofatto et al. 2009). The protein is expressed highly in the adult tegument and exhibits a unique clustered localization pattern in the tegument as revealed by immunoEM analysis (Bhardwaj et al. 2011).

A third candidate tegumental, ATP- and ADP-cleaving enzyme is the ATP diphosphohydrolase homolog SmATPDase1 (Vasconcelos et al. 1996; Vasconcelos et al. 1993). This $\sim 63 \mathrm{kDa}$ protein possesses an $\mathrm{N}$-terminal and a $\mathrm{C}$-terminal transmembrane domain. It was detected in the adult tegument by immunolocalization (DeMarco et al. 2003; Levano-Garcia et al. 2007) and was identified in adult tegument extracts by proteomic analysis (Braschi et al. 2006; van Balkom et al. 
In this work we set out to determine whether degradation of the proinflammatory DAMP, ATP, as well as its pro-thrombotic derivative ADP could be mediated by any, or all, of these schistosome enzymes (SmAP, SmNPP-5 and SmATPDase1). We aimed to determine if schistosomes, like their hosts, exhibit redundancy with regard to exogenous ATP and ADP breakdown. In this work we employed RNAi to suppress the expression of the genes encoding these enzymes in order to measure the ability of each to cleave ATP and ADP.

\section{MATERIALS AND METHODS}

\section{Parasites.}

Snails were provided by the Schistosome Research Reagent Resource Center for distribution by BEI Resources, NIAID, NIH: Schistosoma mansoni, strain NMRI exposed Biomphalaria glabrata snails, strain NMRI, NR-21962. Cercariae were obtained from infected B. glabrata and isolated parasite bodies were prepared as described (Skelly et al. 2003). Parasites were cultured in complete DMEM/F12 medium supplemented with $10 \%$ heat-inactivated fetal bovine serum, 200 $\mathrm{U} / \mathrm{ml}$ penicillin and $200 \mu \mathrm{g} / \mathrm{ml}$ streptomycin, $0.2 \mu \mathrm{M}$ Triiodo-L-thyronine, $1.0 \mu \mathrm{M}$ serotonin and $8 \mu \mathrm{g} / \mathrm{ml}$ human insulin. Parasites were maintained at $37^{\circ} \mathrm{C}$, in an atmosphere of $5 \% \mathrm{CO}_{2}$. Adult male and female parasites were recovered by perfusion from Swiss Webster mice that were infected with 125 cercariae, 7 weeks previously. Work with animals was approved by the Tufts University IACUC; protocol number: G2012-150.

\section{Treatment of parasites with siRNAs.}

Schistosomula and adult worms were treated with synthetic siRNAs targeting SmAP (GenBank accession number EU040139), SmNPP-5 (GenBank accession number EU769293) and SmATPDase1 (GenBank accession number AY323529). An "irrelevant siRNA" was used as a control and its sequence has no identity in the $S$. mansoni genome. The siRNAs were obtained from IDT, Coralville, IA. The siRNAs targeting SmAP, SmNPP-5, and SmATPDase1 are the following: SmAP: 5'-AAGAAATCAGCAGATGAGAGATTTAAT-3', SmNPP-5: 5'TTGATGGATTTCG TTATGATTACTTTG-3', SmATPDase 1: 5'GGACUUUAUGGUUGGGUAUCAGUGA-3'. The control, irrelevant siRNA is: 5'-CT TCCTCTCTTTCTCTCCCTTGTGA-3'.

To deliver the siRNAs, parasites (1000 schistosomula or 10-12 adults/group) in 50-100 $\mu 1$ electroporation buffer (BioRad, CA) containing 2.5 -10 $\mu \mathrm{g}$ siRNA, were electroporated in a $4 \mathrm{~mm}$ cuvette by applying a square wave with a single $20-\mathrm{ms}$ impulse, at $125 \mathrm{~V}$ and at room temperature, as described (Krautz-Peterson et al. 2007; Ndegwa et al. 2007). To suppress SmAP, SmNPP-5 and SmATPDase1 together, $5 \mu \mathrm{g}$ of SmAP and SmNPP-5 siRNA and $10 \mu \mathrm{g}$ SmATPDase1 siRNA were used in the case of adults; $2.5 \mu \mathrm{g}$ of each siRNA was used in the case of schistosomula. In these experiments, an equivalent amount of the irrelevant siRNA was used in the control group. Parasites were transferred to 500-1300 $\mu 1$ complete DMEM/F12 medium after electroporation. After overnight culture, medium was replaced with fresh rich medium (complete $\mathrm{DMEM} / \mathrm{F} 12)$.

\section{Gene expression analysis.}

To assess the level of target gene suppression post-siRNA treatment, RNA and protein were isolated from worm lysates using the PARIS kit (Applied Biosystems, CA). Samples were 
144

145

146

147

148

149

150

151

152

153

154

155

156

157

158

159

160

161

162

163

164

165

166

167

168

169

170

171

172

173

174

175

176

177

178

179

180

181

182

183

184

185

186

187

188

189

homogenized on ice using an RNase free pestle for $\sim 1$ min and the parasite homogenates were split into two halves. One half was used to isolate RNA and the other for protein analysis. RNA was isolated from the parasite homogenate using the PARIS Kit, as per the manufacturer's guidelines. Residual DNA was removed by DNase digestion using a TurboDNA-free kit (Applied Biosystems, TX). cDNA was synthesized using $1 \mu \mathrm{g}$ RNA, an oligo (dT) ${ }_{20}$ primer and Superscript III RT (Invitrogen, CA). Gene expression of SmAP, SmNPP-5 and SmATPDase1 was measured by quantitative real time PCR (qRT-PCR), using custom TaqMan gene expression systems from Applied Biosystems, CA. The primers and probes employed in this research are listed in table 1. The procedure, involving total RNA extraction and quantitative real time PCR, has been described (Krautz-Peterson et al. 2007; Ndegwa et al. 2007). Alpha tubulin was used as the endogenous control gene for relative quantification, as described (Krautz-Peterson et al. 2010), employing the $\Delta \Delta \mathrm{Ct}$ method (Livak \& Schmittgen 2001). Results obtained from parasites treated with irrelevant siRNA were used for calibration. For graphical representation, the $\Delta \Delta \mathrm{Ct}$ values were normalized to controls and expressed as a percentage difference.

Anti-SmAP, anti-SmNPP-5 and anti-SmATPDase1 antibody production.

Anti-SmAP and anti-SmNPP-5 antibodies were generated in rabbits using, in each case, a synthetic peptide as immunogen (Bhardwaj et al. 2011; Bhardwaj \& Skelly 2011). Anti-

SmATPDase1 antibody, generated in mice against recombinant SmATPDase1 protein, was a kind gift from Dr. Sergio Verjovski-Almeida, University of Sao Paulo, Brazil (DeMarco et al. 2003).

\section{Western blotting analysis.}

To monitor protein levels, parasite samples were first homogenized on ice in ice-cold cell disruption buffer (PARIS Kit) followed by incubation for 30 minutes on ice to yield total parasite lysate. Protein content was measured using the BCA Protein Assay Kit (Pierce, IL) according to the manufacturer's instructions. Soluble protein ( $5 \mu \mathrm{g}$ in $20 \mu \mathrm{l}$ SDS-PAGE sample buffer) was subjected to SDS-PAGE under reducing conditions, blotted onto PVDF membrane and blocked using $5 \%$ skim milk in PBS containing $0.1 \%$ Tween 20 (PBST) for $1 \mathrm{~h}$ at room temperature. The membrane was then probed overnight at $4{ }^{\circ} \mathrm{C}$ with anti-SmAP (1:400), or anti-SmNPP-5 (1:200) or SmATPDase1 antiserum (1:10). Following 3 washes with PBST and incubation with donkey anti-rabbit IgG conjugated to horse radish peroxidase (HRP) (GE Healthcare, UK), diluted 1:5000, (for SmAP, and SmNPP-5) and goat anti-mouse IgG conjugated to HRP (Invitrogen) diluted 1:2000, (for SmATPDase1) for 1 hour at $37^{\circ} \mathrm{C}$. Protein bands were visualized using ECL Western Blotting Detection Reagents (GE Healthcare) and X-ray film (ISC BioExpress, Belgium). The same membrane was probed three times to detect SmAP, SmNPP-5 and SmATPDase1. For each re-use, the bound antibody was striped using Restore Western Blot Stripping Buffer from Thermo Scientific (IL, USA) for $4 \mathrm{~h}$ at $37^{\circ} \mathrm{C}$ and then washed in PBS twice for 30 min each. To monitor protein loading per lane, a duplicate gel was stained with Coomassie Brilliant Blue, to visually ensure roughly equivalent protein loading per sample.

\section{Cloning and transient expression of SmATPDase1 in CHO-S cells.}

The complete coding region of SmATPDase 1 (accession number AY323529) was codon optimized for expression in hamster and mouse cells by Genscript and cloned into pUC57 (Genscript USA Inc., Piscataway, NJ). Using this DNA, two constructswere generated for protein expression in mammalian cells: 1) the full-length open reading frame (illustrated in figure 4A) was excised from the pUC57 plasmid using the restriction enzymes NheI and XhoI. These enzyme sites were introduced into the sequence during gene synthesis. The excised DNA was then cloned into the pSecTag2A expression plasmid (Invitrogen) that had been previously digested with the same restriction enzymes. 2) The region encoding just the large extracellular

PeerJ reviewing PDF | (v2014:01:1336:2:0:NEW 28 Feb 2014) 
region of SmATPDase1 (encompassing amino-acids $\mathrm{S}^{66}-\mathrm{Q}^{507}$ and lacking both transmembrane domains, indicated in figure 4A) was amplified by PCR using AccuPrime High Fidelity Taq DNA polymerase (Invitrogen) and cloned at the $A s c$ I and XhoI sites in frame with the Igk-leader sequence in the pSecTag2A expression plasmid. All cloned DNAs were sequenced to verify successful in-frame cloning.

CHO-S cells grown in suspension (Invitrogen) were used for transient SmAPDase1 protein expression. The cells were grown in $30 \mathrm{ml}$ of serum-free Free-Style CHO-S expression medium to 1 X $10^{6}$ cells $/ \mathrm{ml}$. Cells were then transfected with $1 \mu \mathrm{g}$ plasmid DNA $/ \mathrm{ml}$ using Free-Style MAX Transfecting agent according to the manufacturer's instructions (Invitrogen). Seventy two hours later, cells were harvested by centrifugation and cells and culture supernatants were analyzed for SmATPDase1 protein expression. Cell lysates were prepared by cell sonication (3 times, $30 \mathrm{sec}$ each) on ice in assay buffer (20 mM HEPES buffer, $\mathrm{pH} 7.4,1 \%$ Triton X-100, 0.135 $\mathrm{M} \mathrm{NaCl}, 5 \mathrm{mM} \mathrm{KCl}, 1 \mathrm{mM} \mathrm{CaCl} 2$ ). Lysates were incubated on ice for $1 \mathrm{hr}$, centrifuged at $4^{\circ} \mathrm{C}$ for $20 \mathrm{~min}$ at maximum speed. Protein concentration in the recovered supernatants was determined using a BCA kit (Pierce).

\section{SmATPDase1 assay.}

Both ATPase and ADPase activities of the recombinant protein were assayed in 96-well microtiter plates at $37^{\circ} \mathrm{C}$ for $30-120 \mathrm{~min}$. The standard $200 \mu \mathrm{l}$ assay buffer contains $20 \mathrm{mM}$ HEPES buffer, $\mathrm{pH} 7.4,1 \%$ Triton X-100, $0.135 \mathrm{M} \mathrm{NaCl}, 5 \mathrm{mM} \mathrm{KCl}, 1 \mathrm{mM} \mathrm{CaCl}_{2}$, and recombinant SmATPDase1. Reactions were initiated by the addition of ATP or ADP nucleotide solution to a final concentration of $2 \mathrm{mM}$. At different time points thereafter, $10 \mu \mathrm{l}$ aliquots were transferred to $190 \mu \mathrm{l}$ ice-cold water, and stored at $-20^{\circ} \mathrm{C}$ until analyzed. The amount of inorganic phosphate (Pi) released by the enzyme was determine using a Phosphate Colorimetric Assay Kit (BioVision) according to the manufacturer's instructions. Activity was calculated by subtracting the minimal, nonspecific ATP or ADP hydrolysis that was detected in the absence of the enzyme. Nucleotide hydrolysis was linear with time under the assay conditions used and was proportional to the amount of enzyme used. The linear amount of the enzyme was always determined by performing preliminary assays with different amounts of cell lysate (containing 5-50 $\mu \mathrm{g}$ protein). An equivalent amount of lysate from control or mock transfected cells served as control.

\section{SmATPDase1 assays using live parasites and CHO-S cells.}

ATP and ADP hydrolysis activities of live parasites, or intact CHO-S cells (expressing recombinant SmATPDase1), or mock transfected cells, were determined as described above with slight modifications. Briefly, live parasites, or $\mathrm{CHO}-\mathrm{S}$ cells, were first washed 3 times in isotonic wash solution (20 mM HEPES buffer, $\mathrm{pH} 7.4$ containing $0.13 \mathrm{M} \mathrm{NaCl}, 5 \mathrm{mM} \mathrm{KCl}, 1 \mathrm{mM} \mathrm{CaCl}_{2}$, $10 \mathrm{mM}$ Glucose). Next, a specific number of parasites or cells were resuspended in $100 \mu \mathrm{l}$ isotonic wash solution. Reactions were started by the addition of a $100 \mu$ l of the same buffer containing ATP or ADP to produce a final concentration of $2 \mathrm{mM}$. Released inorganic phosphates were measured using the Phosphate Colorimetric Assay Kit (BioVision) according to the manufacturer's instructions.

\section{Characterization of recombinant SmATPDase1 (rSmATPDase1).} Enzyme (10 $\mu \mathrm{g}$ rSmATPDase 1$)$ activity was measured in buffer containing $20 \mathrm{mM} \mathrm{HEPES,} \mathrm{pH}$ 7.4, $1 \%$ Triton $\mathrm{X}-100,0.135 \mathrm{M} \mathrm{NaCl}$ and $5 \mathrm{mM} \mathrm{KCl}$. In some cases this buffer was supplemented with either $1 \mathrm{mM} \mathrm{CaCl}$ or $1 \mathrm{mM} \mathrm{MgCl}_{2}$ or $1 \mathrm{mM}$ EDTA plus $1 \mathrm{mM}$ EGTA or $1 \mathrm{mM} \mathrm{CaCl}_{2}$ plus 10 , 50 or $100 \mu \mathrm{M}$ thapsigargin. Reaction conditions were as described above (SmATPDase1 assay). 
$\mathrm{K}_{\mathrm{m}}$ values for rSmATPDase1 were determined in the standard assay buffer (described earlier) containing different substrate concentrations (0-2.5 mM) of ATP or ADP. $\mathrm{K}_{\mathrm{m}}$ values were calculated using computerized nonlinear regression analysis of the data fitted to the MichaelisMenten equation using Graphpad Prism 4.0.

The effect of $\mathrm{pH}$ on ATP and ADP hydrolysis by rSmATPDase1 was determined in a $200 \mu 1$ enzyme assay using a wide-range buffer system covering the $\mathrm{pH}$ range of 5.5-10.0 (MES, $\mathrm{pH}$ 5.5-6.5; MOPS, pH 6.5-7.5; HEPES, $\mathrm{pH}$ 7.0-8.0, Tris-HCl, $\mathrm{pH}$ 7.5-9.0; Trizma, $\mathrm{pH}$ 9.0; Glycine$\mathrm{NaOH}, \mathrm{pH} 9.0-10)$. Assay solutions contained $20 \mathrm{mM}$ buffer, $1 \%$ Triton X-100, $0.135 \mathrm{M} \mathrm{NaCl}, 5$ $\mathrm{mM} \mathrm{KCl}, 1 \mathrm{mM} \mathrm{CaCl}_{2}$, and $2 \mathrm{mM}$ ATP or ADP with $10 \mu \mathrm{g}$ cell lysate. The reaction was carried out for 30-120 min. Aliquots containing released Pi were assayed at different time points using the phosphate colorimetric assay, as above.

\section{Data analysis.}

For qRT-PCR and Pi release assay data, one way analysis of variance (ANOVA) and Tukey as the post hoc test was used. Other data were analyzed using the Student's $t$-test. In all cases, differences were considered significant when $P$ values $<0.05$.

\section{RESULTS}

\section{Cleavage of exogenous nucleotides by schistosomes}

Living schistosomes possess the ability to catabolize exogenous nucleotides. When live adult males are incubated in the presence of ATP, ADP or AMP they cleave these molecules resulting in the release of inorganic phosphate $(\mathrm{Pi})$, as shown in figure 1A. Likewise, groups of living schistosomula incubated with ATP, ADP or AMP cleave these nucleotides (figure 1B). In the case of both adults and schistosomula, most Pi is generated with ATP as substrate, least is generated with AMP as a substrate and an intermediate amount from ADP. Under the conditions used, we detect no background generation of inorganic phosphate in control samples lacking parasites when ATP and AMP are used and only negligible levels of Pi $(<5 \mathrm{nmol})$ when ADP is added. One model for schistosome catabolism of these metabolites suggests that three different enzymes with overlapping function may be involved. This proposed pathway for catabolism of exogenous ATP, ADP and AMP by intravascular schistosomes is shown in figure 1C.

\section{SmAP, SmNPP-5 and SmATPDase1 gene suppression using RNAi}

In order to uncover which of the enzymes is involved in each step of the exogenous nucleotide catabolism pathway shown in figure 1C, the genes encoding these enzymes were first subjected to suppression using RNAi. Suppression was monitored by qRT-PCR 7 days after treatment and results are shown in figure $2 \mathrm{~A}-\mathrm{C}$. In each case, gene expression is depicted relative to the control group treated with an irrelevant siRNA (set at $100 \%$, grey bars in figure 2 ). Relative to the control, it is clear that all 3 targeted genes have been well suppressed $(P<0.05$, in each case). Figure 2A illustrates results for SmAP; the group treated with a specific SmAP siRNA exhibits $\sim 90 \%$ lower SmAP gene expression relative to the control group. This is the case when the SmAP siRNA is used alone (lane SmAP, figure 2) or in combination with siRNAs also targeting SmNPP-5 and SmATPDase1 (lane marked "all 3", figure 2A). Similarly, from figure 2B it is clear that when SmNPP-5 is targeted with specific SmNPP-5 siRNA, >90\% suppression is observed. Again, this is the case both when SmNPP-5 is targeted with SmNPP-5 siRNA alone (lane SmNPP-5, fig 2B) or with siRNAs also targeting SmAP and SmATPDase1 (lane "all 3", fig 2B). Finally, similar results are seen for SmATPDase1 in figure $2 \mathrm{C}$; in this case $\sim 80 \%$ suppression is seen when this gene is targeted with SmATPDase1 siRNA either alone (lane 
SmATPD, fig 2C) or in addition to siRNAs targeting SmAP and SmNPP-5 ("all 3", fig 2C). Gene knockdown was specific; siRNAs targeting SmAP have no significant effect on SmNPP-5 or SmATPDase1 levels compared to control; suppressing SmNPP-5 did not appreciably impact the SmAP or SmATPDase1 genes. In a similar manner, targeting SmATPDase1 led to its specific knockdown without significant impact on the SmAP or SmNPP-5 genes. Suppression was consistently better for SmAP and SmNPP-5 (>90\%) versus SmATPDase1 ( $\sim 80 \%)$. Our attempts to suppress the SmATPDase1 gene still further by using greater amounts of siRNA (up to $35 \mu \mathrm{g}$ ), or different siRNAs, were not successful (data not shown).

In order to assess the impact of gene suppression at the protein level, target-specific antibodies were used in western blotting analyses and results are shown in figure 2D. Protein extracts of control and the triply-suppressed parasites (SmAP, SmNPP-5 and SmATPDase, lane "All 3" in figure 2D) were probed with anti-SmAP, anti-SmNPP-5 or anti-SmATPDase1 antibodies. It is clear that, in all cases, the siRNA treatment resulted in a diminution in protein levels compared to parasites treated either with irrelevant, control siRNA (figure 2D, control) or with no siRNA (figure 2D, None). This is the case for SmAP (Figure 2D, top row), SmNPP-5 (second row) and SmATPDase1 (third row). The bottom panel in figure 2D shows a fragment of a Coomassie Blue stained polyacrylamide gel, distant from the location of any of the targets, to illustrate that all lanes contained roughly equivalent amounts of parasite protein.

Parasites with each of the surface enzyme genes suppressed (either separately or all together) exhibited no morphological differences compared to controls. This suggests that high levels of expression of these genes are not very important for the worms in culture.

\section{SmATPDase1 alone is responsible for exogenous ATP and ADP degradation.}

The ability of suppressed or control parasites in culture to degrade exogenously added ATP (2 $\mathrm{mM}$ ) was measured over time. The rate of Pi release per parasite in culture is shown in figure $3 \mathrm{~A}$. Each control parasite treated with an irrelevant siRNA generates an average of $\sim 67 \mathrm{nmol} \mathrm{Pi} / \mathrm{hr}$ (Figure 3A, Control). Likewise, control parasites treated with no siRNA (figure 3A, None) as well as parasites whose SmAP gene or SmNPP-5 gene has been suppressed (figure 3A, SmAP and SmNPP-5) all generate a similar amount of Pi. In contrast, parasites whose SmATPDase1 gene has been suppressed (figure 3A, SmATPD, grey bar) are significantly impaired in their ability to cleave exogenous ATP and liberate Pi $(P<0.05)$; only about $50 \%$ of the ATPase activity was detected, compared to controls. These data show that SmATPDase, but not SmAP or SmNPP-5, degrades exogenous ATP.

Next, the ability of suppressed or control parasites in culture to degrade exogenously added ADP $(2 \mathrm{mM})$ was measured over time. Again, the amount of Pi released in culture was measured and results are shown in figure $3 \mathrm{~B}$. The data for Pi release, when ADP is the substrate, are broadly similar to those obtained when ATP is used. Parasites whose SmATPDase1 gene is suppressed (figure $3 \mathrm{~B}$, SmATPD, grey bar) again generate about $50 \%$ of the Pi released by those parasites treated with a control, irrelevant siRNA (figure $3 \mathrm{~B}$, control, $P<0.05$ ). Parasites whose SmNPP-5 gene or SmAP gene were suppressed (figure 3B, SmNPP-5 and SmAP) generate Pi at a rate not significantly different from the control treated group. These data show that, as for ATP, SmATPDase1, not SmAP or SmNPP-5, degrades exogenous ADP.

\section{Characterization of recombinant SmATPDase1 expressed in CHO cells}

From the data presented, it is clear that SmATPDase1 is a key enzyme in the catabolic pathway under study. In order to characterize the enzyme further, efforts were made to express the protein 
in CHO-S cells in two different forms - in full length form (from residue 1 through 544, as illustrated in figure 4A, top panel) and as a secreted form lacking the predicted $\mathrm{N}$-terminal and $\mathrm{C}$ terminal transmembrane (TM) domains (i.e. from residue $\mathrm{S}^{66}$ through $\mathrm{Q}^{507}$, indicated in figure $4 \mathrm{~A}$, bottom panel). Roughly $72 \mathrm{~h}$ after cell transfection with plasmid constructs expressing the fulllength or the secreted form, ATP or ADP was added to CHO cell lysates (containing $10 \mu \mathrm{g}$ protein) and Pi release measured over time. Control cells were not transfected with any plasmid. As shown in figure $4 \mathrm{~B}$ and $\mathrm{C}$, only lysate from cells expressing the full length protein exhibited activity. This was the case following either ATP addition to the assay (figure 4B, grey bar) or following ADP addition to the assay (figure 4C, grey bar). Any secreted protein was inactive; lysate from cells targeted to express the secreted protein displayed activity indistinguishable from that of control cell lysate (black versus white bars, figure 4B and C).

The expectation is that some of the full length, recombinant SmATPDase1 (rSmATPDase) ectoenzyme will be expressed on the plasma membrane of the transfected $\mathrm{CHO}$ cells. To look for activity at the surface of living CHO cells, transfected and control cells were plated at $75 \times 10^{3}$ or $150 \times 10^{3}$ per well and either ATP (inset figure 4B) or ADP (inset, figure 4C) was added in a Pi release assay. It is clear that the living transfected cells (grey bars, figure 4B and $\mathrm{C}$, insets) can cleave both ATP (figure 4B, inset) and ADP (figure 4C, inset) to release Pi at substantially greater levels than controls (white bars, figure $4 \mathrm{~B}$ and $\mathrm{C}$, insets). As expected, in both cases, greater numbers of cells used in the assay $\left(150 \times 10^{3}\right.$ versus $75 \times 10^{3}$, figure $4 \mathrm{~B}$ and $\mathrm{C}$, insets $)$ yield proportionally greater Pi release.

The activity of rSmATPDase1 was measured under different experimental conditions. As demonstrated in figure 5, the catalytic activity exhibited by SmATPDase1 in the CHO cell lysate towards ATP (figure 5A) and ADP (figure 5D) was markedly increased by the addition of $1 \mathrm{mM}$ $\mathrm{Mg}^{++}$to the mixture and (for ATP) increased still further by the addition of $1 \mathrm{mM} \mathrm{Ca}^{++}$. Chelating these ions from the original lysate with the addition of EDTA and EGTA greatly reduced the activities detected (figure 5A and D). Adding thapsigargin to the lysate (at 10,50 or $100 \mu \mathrm{M}$ ) had a minor inhibitory effect ( $\sim 20 \%$ at all concentrations tested) on ATP hydrolysis and an even smaller effect $(\sim 5 \%)$ on ADP hydrolysis. Only results obtained using the highest thapsigargin concentration tested $(100 \mu \mathrm{M})$ are shown. The $\mathrm{K}_{\mathrm{m}}$ of recombinant SmATPDase 1 is $0.4 \pm 0.02$ $\mathrm{mM}$ for ATP (figure 5B) and $0.252 \pm 0.02 \mathrm{mM}$ for ADP (figure 5E). Both ATP and ADP catalytic activities display $\mathrm{pH}$ optima in the alkaline range; the ATPase activity is maximal at $\mathrm{pH} \geq 8.5$ (figure 5C) and the ADPase activity is maximal at $\mathrm{pH} \geq 7.5$ (figure 5F).

\section{DISCUSSION}

The migration of intravascular schistosomes can stress blood vessel endothelia (Bloch 1980; Smith \& von Lichtenberg 1974) likely leading to the release of host molecules, such as ATP, that signal cell damage (Bhardwaj \& Skelly 2009). In the extracellular environment, ATP is a potent proinflammatory mediator and its byproduct (ADP) is potently pro-thrombotic. It has been hypothesized that schistosomes have evolved to impede host immunity and thrombus formation by degrading these host signaling molecules using nucleotide metabolizing enzymes expressed on their surface (Bhardwaj \& Skelly 2009).

It has long been known that schistosome tegumental extracts do possess ATP and ADP hydrolyzing capabilities and that living worms can deplete exogenous ATP and ADP (Vasconcelos et al. 1993). Here we confirm that living parasites (both adults and schistosomula) can degrade exogenous ATP, ADP and AMP. In the case of vertebrates, ectoenzymes belonging 
366

367

368

369

370

371

372

373

374

375

376

377

378

379

380

381

382

383

384

385

386

387

388

389

390

391

392

393

394

395

396

397

398

399

400

401

402

403

404

405

406

407

408

to three different classes are known to engage in the extracellular ATP degradation pathway (Bours et al. 2006). These are alkaline phosphatase, phosphodiesterase and

ATPdiphosphohydrolase. In what appears to be considerable redundancy in vertebrates, enzymes belonging to these three classes can all mediate ATP and ADP breakdown while two of the three can mediate AMP breakdown (Bours et al. 2006). Using this literature as a guide, we hypothesized that the exogenous ATP degradation pathway in schistosomes could similarly be mediated by several known tegumental enzymes belonging to these enzyme classes. These are SmAP, SmNPP-5 and SmATPDase1.

In this paper, the hypothesis that schistosomes possess equivalent redundancy to vertebrates in their ability to degrade extracellular ATP and ADP was tested. First, RNAi was employed to suppress the expression of all 3 ectoenzyme genes (either alone or in combination). The expression of each gene is robustly and specifically suppressed both when that gene is targeted by itself or with other genes. Suppression at the RNA level is confirmed by quantitative real-time PCR analysis; suppression at the protein level is seen by western blotting analysis.

When parasites that have had all three ectoenzyme genes suppressed were maintained in culture for up to 4 weeks they exhibited no morphological differences when compared to controls. This suggests that normal expression of the genes encoding the three ectoenzymes is not essential for worm survival in culture and is in agreement with the hypothesis that these enzymes are primarily important for parasites within the vertebrate host where they act to minimize host purinergic signaling.

The first step in the pathway under study here is the catabolism of ATP to ADP. In order to decipher which of the three enzymes participate in this step, their genes were suppressed using RNAi. Next, the ability of the SmAP- or SmNPP-5- or SmATPDase-suppressed parasites to degrade ATP (added to the assay buffer) was compared with the ability of controls to degrade ATP. The results are clear - of these 3 gene knockdown conditions, it is only following SmATPDase1 knockdown that parasites exhibit a reduced ability to cleave exogenous ATP, in comparison to controls. The SmAP- and SmNPP-5-suppressed adult parasites were not impacted in their ATP-hydrolyzing ability, which was comparable to the controls. Only the ATP degrading ability of the SmATPDase1-suppressed parasites was significantly reduced. Thus, unlike vertebrates, schistosomes utilize just one ectoenzyme to cleave ATP. There is no redundancy in schistosomes at this step.

The second step in the pathway involves the cleavage of ADP. A similar experiment to that just described for ATP was undertaken; the ability of SmAP- or SmNPP-5- or SmATPDasesuppressed parasites versus controls to degrade ADP (added to the assay buffer) was compared. It was observed that the SmATPDase-suppressed group alone exhibited a lessened ability to cleave ADP. The SmAP- and SmNPP-5 suppressed parasites had no impairment in ADP cleavage compared to controls. As for ATP cleavage, this second ADP-cleavage step is also non-redundant in schistosomes. SmATPDase, in addition to being an ATPase, is also an ADPase.

The final step in the pathway is the cleavage of AMP to generate adenosine. In previous work it has been established that SmAP fulfills this function (Bhardwaj \& Skelly 2011). Thus the final pathway in schistosomes is simpler than that observed in vertebrates and is illustrated in figure 6. The third enzyme, SmNPP-5 does not participate in this pathway. While its function at the surface of the intravascular worms is not known, SmNPP-5 does fulfill an important role for 
schistosomes since it has been shown that parasites whose SmNPP-5 gene is suppressed fail to establish a robust infection in mice (Bhardwaj et al. 2011).

To confirm that SmATPDase1 is a true apyrase i.e. it can cleave ATP and ADP to yield AMP and $\mathrm{Pi}$, as suggested by the gene knockdown experiments, a recombinant form of the protein was expressed in CHO-S cells. Attempts were made to generate a soluble form of SmATPDase1 (lacking transmembrane domains but retaining all key enzymatic motifs). While this goal was achieved, the soluble protein was enzymatically inactive, likely due to incorrect post-translational handling. In contrast, a full-length version of SmATPDase1 was generated in CHO-S cells that was active. The retention of the two terminal, transmembrane domains in this full-length recombinant protein seems important for proper folding and may help to maintain the protein in an enzymatically favorable conformation. There is firm evidence from work with ATPDases in other systems that the interaction of the transmembrane domains and their mobility in a lipid bilayer regulate enzyme catalysis (Knowles 2011). For instance, the extracellular domain of the chicken NTPDase8 enzyme has a small fraction of the activity of the full length enzyme (Li et al. 2010). At least some of the full length SmATPDase1 ectoenzyme expressed here is found in the plasma membrane of the CHO-S cells such that live intact cells expressing the protein display both ATP and ADP cleaving capabilities.

The ability of recombinant SmATPDase1 expressed in CHO-S cells to hydrolyze ATP and ADP was found to be enhanced by the addition of divalent cations to the mixture; adding $\mathrm{Ca}^{++}$or $\mathrm{Mg}^{++}$ to the rSmATPDase1 preparation greatly increases activity. Adding $\mathrm{Mg}^{++}$or $\mathrm{Ca}^{++}$to schistosome tegument preparations had previously been shown to promote ATPase and ADPase activity (Torres et al. 1998; Vasconcelos et al. 1993). As reported here, removing these cations from the rSmATPDase1 preparation by the addition of the chelating agents EDTA plus EGTA effectively shuts down the enzyme. The fact that SmATPDase1 is a calcium-activated plasma membranebound enzyme again confirms it as a member of the apyrase family. Earlier substrate competition experiments (ATP versus ADP) involving schistosome tegument extracts, as well as comparative heat inactivation profiles for ATP versus ADP hydrolytic activities using these extracts, led to the hypothesis that a single enzyme in the tegument was responsible for degrading both ATP and ADP (Martins et al. 2000; Vasconcelos et al. 1993). Our work confirms this hypothesis. Furthermore, under physiological conditions the $\mathrm{K}_{\mathrm{m}}$ of rSmATPDase1 for ATP is $0.4 \pm 0.02 \mathrm{mM}$ and for ADP is $0.252 \pm 0.02 \mathrm{mM}$ and these values are almost identical to those reported for the ATPase activity and the ADPase activity of adult $S$. mansoni tegumental extracts $(0.25 \mathrm{mM}$ for ADP and $0.45 \mathrm{mM}$ for ATP, (Vasconcelos et al. 1993).

As discussed, the apyrase activity detected in schistosome tegument membrane preparations has a very similar profile to that described here for rSmATPDase1. One difference is apparent however; the ATPase activity of the tegument preparation (but not its ADPase activity) has been reported to be inhibited by thapsigargin in a dose dependent manner (Martins et al. 2000). Inhibition of $\sim 70 \%$ was seen with $100 \mu \mathrm{M}$ thapsigargin (Martins et al. 2000). This finding was a surprise since thapsigargin is best known as a specific inhibitor of sarco/endoplasmic reticulum $\mathrm{Ca}^{++}$(SERCA) ATPases and not of apyrases (Rogers et al. 1995). Our finding is that there is no dose-dependent inhibitory effect of thapsigargin on rSmATPDase1 activity; at all thapsigargin concentrations tested $(10-100 \mu \mathrm{M})$ ATPase activity is decreased by $\sim 20 \%$ and ADPase activity by $\sim 5 \%$. Our data show that, as for other apyrases, the SmATPDase1 enzyme is not intrinsically inhibitable by thapsigargin in a dose dependent manner. The inhibition reported (Martins et al. $\underline{2000}$ ) is likely related to the use of tegument preparations rather than recombinant enzyme. 
As shown here, both ATP and ADP cleavage activities of rSmATPDase1 are more pronounced in an alkaline environment. Earlier, the ATPase activity detected in adult schistosome tegumental membrane extracts was reported to be similarly enhanced under alkaline conditions (Cesari et al. 1981). Furthermore, other enzyme activities (alkaline phosphatase and phosphodiesterase) detectable in tegument extracts are likewise greatest at $\mathrm{pH}>9$ (Cesari et al. 1981). Why the three ectoenzymes SmAP, SmNPP-5 and SmATPDase1, expressed at the host-parasite interface, should all display highest activity under alkaline conditions is unclear. Perhaps schistosomes in vivo maintain an alkaline environment immediately around them in which these enzymes optimally act and which has some selective advantage for the worms.

Our work demonstrates that the three ecto-enzyme genes SmAP, SmNPP-5 and SmATPDase1 can all be specifically and strongly knocked down using target specific siRNAs. It is noteworthy that roughly equivalent suppression is obtained irrespective of whether each gene is targeted alone or together with the other two targets. In other words there is no compromise in suppression efficiency when all three genes are targeted together, demonstrating that the RNAi machinery in schistosomes is not saturated by multiple siRNAs targeting different mRNAs at the same time.

Just as important for schistosomes as the elimination of potentially damaging host signaling molecules like ATP and ADP by SmATPDase 1 may be the generation of adenosine from AMP via SmAP. This is because many of the proinflammatory effects of ATP on immune cells can be suppressed or reversed by adenosine (Reviewed in (Bours et al. 2006; Hasko \& Cronstein 2004). Extracellular adenosine can impede the chemotactic responses of macrophages and monocytes and can inhibit both their production of pro-inflammatory cytokines as well as macrophage proliferation, phagocytosis and lysosymal enzyme secretion (Bours et al. 2006; Riches et al. 1985). Extracellular adenosine can inhibit the production of reactive nitrogen species and reactive oxygen species by monocytes/macrophages and neutrophils (Bours et al. 2006; Flamand et al. 2000). In addition, adenosine can impede lymphocyte adhesion and attenuate the proliferative and cytotoxic responses of activated T cells (Bours et al. 2006; Hasko \& Cronstein 2004).

On a more mundane level, the adenosine generated by this pathway may be directly taken up by schistosomes as food (Levy \& Read 1975b). The ATP catabolic pathway may be used to generate purine derivatives in the vicinity of the worms that can then be easily imported and this function may have particular importance for schistosomes since the parasites are unable to synthesize purines de novo (Levy \& Read 1975a). The hypotheses that any adenosine generated via this pathway may be taken in by the parasites as food or may act to impede host purinergic signaling are not mutually exclusive.

Since the 3 ecto-enzymes may make good vaccine candidates, all have been purified from inclusion bodies following their expression as recombinant proteins in E. coli (Rofatto et al. $\underline{2013}$ ). In vaccine trials, immunization with the isolated individual proteins, or with all three proteins combined, did not reduce the worm burden of challenged mice. However, immunization with SmAP alone or with all three proteins together, when combined with subcurative treatment with the drug praziquantel, was able to reduce worm burdens by $\sim 40 \%$ (Rofatto et al. 2013).

An ability to cleave ATP and/or ADP in the extracellular environment has been described in several pathogens. For example ecto-ATPase activity has been described in the protozoan parasites Toxoplasma gondii (Bermudes et al. 1994), Leishmania amazonensis (Berredo-Pinho et al. 2001), Trichomonas vaginalis (de Jesus et al. 2002) and Cryptosporidum parvum (Manque et al. 2012) and in several bacterial pathogens including Mycobacterium bovis (Zaborina et al. 
1999), Vibrio cholera (Punj et al. 2000), Staphylococcus aureus (Thammavongsa et al. 2009), and Legionella pneumophilia (Vivian et al. 2010). Similarly, blood-feeding ectoparasites are known to release a repertoire of nucleotide-metabolizing enzymes in their saliva (Andersen et al. 2007; de Araujo et al. 2012). The parasitic nematode Trichinella spiralis secretes a panel of nucleotide metabolizing enzymes (Gounaris 2002). Thus a conserved feature of several pathogens, including schistosomes, is an ability to control local ATP and ADP levels, perhaps to thereby inhibit inflammation and thrombosis and protect the pathogens. Identifying chemical inhibitors of SmATPDase1 to negate the worm's ability to degrade exogenous pro-inflammatory and prothrombotic nucleotides may offer a novel therapeutic option to treat schistosomiasis.

\section{Acknowledgements}

Infected snails were provided by the Biomedical Research Institute via the NIAID schistosomiasis resource center under NIH-NIAID Contract No. HHSN272201000005I. We thank Dr. Chuck Shoemaker for helpful discussion and Dr. Sergio Verjovski-Almeida, University of Sao Paulo, Brazil for the anti-SmATPDase1 antibody.

\section{REFERENCES}

Andersen JF, Hinnebusch BJ, Lucas DA, Conrads TP, Veenstra TD, Pham VM, and Ribeiro JM. 2007. An insight into the sialome of the oriental rat flea, Xenopsylla cheopis (Rots). BMC Genomics 8:102.

Bermudes D, Peck KR, Afifi MA, Beckers CJ, and Joiner KA. 1994. Tandemly repeated genes encode nucleoside triphosphate hydrolase isoforms secreted into the parasitophorous vacuole of Toxoplasma gondii. J Biol Chem 269:29252-29260.

Berredo-Pinho M, Peres-Sampaio CE, Chrispim PP, Belmont-Firpo R, Lemos AP, Martiny A, Vannier-Santos MA, and Meyer-Fernandes JR. 2001. A Mg-dependent ecto-ATPase in Leishmania amazonensis and its possible role in adenosine acquisition and virulence. Arch Biochem Biophys 391:16-24.

Bhardwaj R, Krautz-Peterson G, Da'dara A, Tzipori S, and Skelly PJ. 2011. Tegumental Phosphodiesterase SmNPP-5 Is a Virulence Factor for Schistosomes. Infection and immunity 79:4276-4284.

Bhardwaj R, and Skelly PJ. 2009. Purinergic signaling and immune modulation at the schistosome surface? Trends in parasitology 25:256-260.

Bhardwaj R, and Skelly PJ. 2011. Characterization of schistosome tegumental alkaline phosphatase (SmAP). PLoS neglected tropical diseases 5:e1011.

Bloch EH. 1980. In vivo microscopy of schistosomiasis. II. Migration of Schistosoma mansoni in the lungs, liver, and intestine. Am J Trop Med Hyg 29:62-70.

Bours MJ, Swennen EL, Di Virgilio F, Cronstein BN, and Dagnelie PC. 2006. Adenosine 5'triphosphate and adenosine as endogenous signaling molecules in immunity and inflammation. Pharmacol Ther 112:358-404.

Braschi S, Curwen RS, Ashton PD, Verjovski-Almeida S, and Wilson A. 2006. The tegument surface membranes of the human blood parasite Schistosoma mansoni: a proteomic analysis after differential extraction. Proteomics 6:1471-1482.

Braschi S, and Wilson RA. 2006. Proteins exposed at the adult schistosome surface revealed by biotinylation. Mol Cell Proteomics 5:347-356.

Burnstock G. 2006. Pathophysiology and therapeutic potential of purinergic signaling. Pharmacol Rev 58:58-86. 
Castro-Borges W, Dowle A, Curwen RS, Thomas-Oates J, and Wilson RA. 2011. Enzymatic shaving of the tegument surface of live schistosomes for proteomic analysis: a rational approach to select vaccine candidates. PLoS neglected tropical diseases 5:e993.

Cesari IM. 1974. Schistosoma mansoni: distribution and characteristics of alkaline and acid phosphatase. Exp Parasitol 36:405-414.

Cesari IM, Simpson AJ, and Evans WH. 1981. Properties of a series of tegumental membranebound phosphohydrolase activities of Schistosoma mansoni. Biochem J 198:467-473.

Cohen C, Reinhardt B, Castellani L, Norton P, and Stirewalt M. 1982. Schistosome surface spines are "crystals" of actin. J Cell Biol 95:987-988.

de Araujo CN, Bussacos AC, Sousa AO, Hecht MM, and Teixeira AR. 2012. Interactome: Smart hematophagous triatomine salivary gland molecules counteract human hemostasis during meal acquisition. J Proteomics 75:3829-3841.

de Jesus JB, de Sa Pinheiro AA, Lopes AH, and Meyer-Fernandes JR. 2002. An ectonucleotide ATP-diphosphohydrolase activity in Trichomonas vaginalis stimulated by galactose and its possible role in virulence. $Z$ Naturforsch $C$ 57:890-896.

DeMarco R, Kowaltowski AT, Mortara RA, and Verjovski-Almeida S. 2003. Molecular characterization and immunolocalization of Schistosoma mansoni ATPdiphosphohydrolase. Biochem Biophys Res Commun 307:831-838.

Dusanic DG. 1959. Histochemical observations of alkaline phosphatase in Schistosoma mansoni. J Infect Dis 105:1-8.

Espinoza B, Tarrab-Hazdai R, Silman I, and Arnon R. 1988. Acetylcholinesterase in Schistosoma mansoni is anchored to the membrane via covalently attached phosphatidylinositol. Mol Biochem Parasitol 29:171-179.

Flamand N, Boudreault S, Picard S, Austin M, Surette ME, Plante H, Krump E, Vallee MJ, Gilbert C, Naccache P, Laviolette M, and Borgeat P. 2000. Adenosine, a potent natural suppressor of arachidonic acid release and leukotriene biosynthesis in human neutrophils. Am J Respir Crit Care Med 161:S88-94.

Gachet C. 2006. Regulation of platelet functions by P2 receptors. Annu Rev Pharmacol Toxicol 46:277-300.

Gounaris K. 2002. Nucleotidase cascades are catalyzed by secreted proteins of the parasitic nematode Trichinella spiralis. Infection and immunity 70:4917-4924.

Gryseels B, Polman K, Clerinx J, and Kestens L. 2006. Human schistosomiasis. Lancet 368:1106-1118.

Hanley PJ, Musset B, Renigunta V, Limberg SH, Dalpke AH, Sus R, Heeg KM, Preisig-Muller R, and Daut J. 2004. Extracellular ATP induces oscillations of intracellular $\mathrm{Ca} 2+$ and membrane potential and promotes transcription of IL-6 in macrophages. Proc Natl Acad Sci U S A 101:9479-9484.

Hasko G, and Cronstein BN. 2004. Adenosine: an endogenous regulator of innate immunity. Trends Immunol 25:33-39.

Hockley DJ, and McLaren DJ. 1973. Schistosoma mansoni: changes in the outer membrane of the tegument during development from cercaria to adult worm. Int J Parasitol 3:13-25.

Joseph M, Auriault C, Capron A, Vorng H, and Viens P. 1983. A new function for platelets: IgEdependent killing of schistosomes. Nature 303:810-812.

Knowles AF. 2011. The GDA1_CD39 superfamily: NTPDases with diverse functions. Purinergic Signal 7:21-45.

Krautz-Peterson G, Radwanska M, Ndegwa D, Shoemaker CB, and Skelly PJ. 2007. Optimizing gene suppression in schistosomes using RNA interference. Mol Biochem Parasitol 153:194-202. 
Krautz-Peterson G, Simoes M, Faghiri Z, Ndegwa D, Oliveira G, Shoemaker CB, and Skelly PJ. 2010. Suppressing glucose transporter gene expression in schistosomes impairs parasite feeding and decreases survival in the mammalian host. PLoS pathogens 6:e1000932.

Levano-Garcia J, Mortara RA, Verjovski-Almeida S, and DeMarco R. 2007. Characterization of Schistosoma mansoni ATPDase2 gene, a novel apyrase family member. Biochem Biophys Res Commun 352:384-389.

Levi-Schaffer F, Tarrab-Hazdai R, Schryer MD, Arnon R, and Smolarsky M. 1984. Isolation and partial characterization of the tegumental outer membrane of schistosomula of Schistosoma mansoni. Mol Biochem Parasitol 13:283-300.

Levy MG, and Read CP. 1975a. Purine and pyrimidine transport in Schistosoma mansoni. $J$ Parasitol 61:627-632.

Levy MG, and Read CP. 1975b. Relation of tegumentary phosphohydrolase to purine and pyrimidine transport in Schistosoma mansoni. J Parasitol 61:648-656.

Li CS, Lee Y, and Knowles AF. 2010. The stability of chicken nucleoside triphosphate diphosphohydrolase 8 requires both of its transmembrane domains. Biochemistry 49:134146.

Livak KJ, and Schmittgen TD. 2001. Analysis of relative gene expression data using real-time quantitative PCR and the 2(-Delta Delta C(T)) Method. Methods 25:402-408.

Lohman AW, Billaud M, and Isakson BE. 2012. Mechanisms of ATP release and signalling in the blood vessel wall. Cardiovasc Res 95:269-280.

Mahaut-Smith MP, Ennion SJ, Rolf MG, and Evans RJ. 2000. ADP is not an agonist at P2X(1) receptors: evidence for separate receptors stimulated by ATP and ADP on human platelets. Br J Pharmacol 131:108-114.

Manque PA, Woehlbier U, Lara AM, Tenjo F, Alves JM, and Buck GA. 2012. Identification and characterization of a novel calcium-activated apyrase from Cryptosporidium parasites and its potential role in pathogenesis. PLoS One 7:e31030.

Martins SM, Torres CR, and Ferreira ST. 2000. Inhibition of the ecto-ATPdiphosphohydrolase of Schistosoma mansoni by thapsigargin. Biosci Rep 20:369-381.

Morris GP, and Threadgold LT. 1968. Ultrastructure of the tegument of adult Schistosoma mansoni. J Parasitol 54:15-27.

Ndegwa D, Krautz-Peterson G, and Skelly PJ. 2007. Protocols for gene silencing in schistosomes. Exp Parasitol 117:284-291.

Pellegrino J, and Coelho PM. 1978. Schistosoma mansoni: wandering capacity of a worm couple. J Parasitol 64:181-182.

Pujol FH, Liprandi F, Rodriguez M, and Cesari IM. 1990. Production of a mouse monoclonal antibody against the alkaline phosphatase of adult Schistosoma mansoni. Mol Biochem Parasitol 40:43-52.

Punj V, Zaborina O, Dhiman N, Falzari K, Bagdasarian M, and Chakrabarty AM. 2000. Phagocytic cell killing mediated by secreted cytotoxic factors of Vibrio cholerae. Infection and immunity 68:4930-4937.

Riches DW, Watkins JL, Henson PM, and Stanworth DR. 1985. Regulation of macrophage lysosomal secretion by adenosine, adenosine phosphate esters, and related structural analogues of adenosine. $J$ Leukoc Biol 37:545-557.

Rofatto HK, Araujo-Montoya BO, Miyasato PA, Levano-Garcia J, Rodriguez D, Nakano E, Verjovski-Almeida S, Farias LP, and Leite LC. 2013. Immunization with tegument nucleotidases associated with a subcurative praziquantel treatment reduces worm burden following Schistosoma mansoni challenge. PeerJ 1:e58. 
Rofatto HK, Tararam CA, Borges WC, Wilson RA, Leite LC, and Farias LP. 2009. Characterization of phosphodiesterase-5 as a surface protein in the tegument of Schistosoma mansoni. Mol Biochem Parasitol 166:32-41.

Rogers TB, Inesi G, Wade R, and Lederer WJ. 1995. Use of thapsigargin to study Ca2+ homeostasis in cardiac cells. Biosci Rep 15:341-349.

Senft AW, Philpott DE, and Pelofsky AH. 1961. Electron microscopy of the integument, flame cells, and gut of Schistosoma mansoni. J Parasitol 47:217-229.

Silk MH, Spence IM, and Gear JH. 1969. Ultrastructural studies of the blood fluke--Schistosoma mansoni. I. The integument. S Afr J Med Sci 34:1-10.

Skelly PJ, Da'dara A, and Harn DA. 2003. Suppression of cathepsin B expression in Schistosoma mansoni by RNA interference. Int J Parasitol 33:363-369.

Smith JH, and von Lichtenberg F. 1974. Observations on the ultrastructure of the tegument of Schistosoma mansoni in mesenteric veins. Am J Trop Med Hyg 23:71-77.

Thammavongsa V, Kern JW, Missiakas DM, and Schneewind O. 2009. Staphylococcus aureus synthesizes adenosine to escape host immune responses. J Exp Med 206:2417-2427.

Torres CR, Vasconcelos EG, Ferreira ST, and Verjovski-Almeida S. 1998. Divalent cation dependence and inhibition of Schistosoma mansoni ATP diphosphohydrolase by fluorosulfonylbenzoyl adenosine. Eur J Biochem 251:516-521.

van Balkom BW, van Gestel RA, Brouwers JF, Krijgsveld J, Tielens AG, Heck AJ, and van Hellemond JJ. 2005. Mass spectrometric analysis of the Schistosoma mansoni tegumental sub-proteome. J Proteome Res 4:958-966.

Vasconcelos EG, Ferreira ST, Carvalho TM, Souza W, Kettlun AM, Mancilla M, Valenzuela MA, and Verjovski-Almeida S. 1996. Partial purification and immunohistochemical localization of ATP diphosphohydrolase from Schistosoma mansoni. Immunological cross-reactivities with potato apyrase and Toxoplasma gondii nucleoside triphosphate hydrolase. J Biol Chem 271:22139-22145.

Vasconcelos EG, Nascimento PS, Meirelles MN, Verjovski-Almeida S, and Ferreira ST. 1993. Characterization and localization of an ATP-diphosphohydrolase on the external surface of the tegument of Schistosoma mansoni. Mol Biochem Parasitol 58:205-214.

Vennervald BJ, and Dunne DW. 2004. Morbidity in schistosomiasis: an update. Curr Opin Infect Dis 17:439-447.

Vivian JP, Riedmaier P, Ge H, Le Nours J, Sansom FM, Wilce MC, Byres E, Dias M, Schmidberger JW, Cowan PJ, d'Apice AJ, Hartland EL, Rossjohn J, and Beddoe T. 2010. Crystal structure of a Legionella pneumophila ecto -triphosphate diphosphohydrolase, a structural and functional homolog of the eukaryotic NTPDases. Structure 18:228-238.

Yegutkin GG. 2008. Nucleotide- and nucleoside-converting ectoenzymes: Important modulators of purinergic signalling cascade. Biochim Biophys Acta 1783:673-694.

Zaborina O, Li X, Cheng G, Kapatral V, and Chakrabarty AM. 1999. Secretion of ATP-utilizing enzymes, nucleoside diphosphate kinase and ATPase, by Mycobacterium bovis BCG: sequestration of ATP from macrophage P2Z receptors? Mol Microbiol 31:1333-1343. 
In the absence of parasites, no or negligible $(<5 \mathrm{nmol}) \mathrm{Pi}$ is detected. The data shown are representative of at least three independent experiments. $C$, The proposed pathway in schistosomes for exogenous ATP catabolism via ADP and AMP to adenosine. The following three schistosome tegumental ectoenzymes are hypothesized to be involved: $\operatorname{SmAP}(S$. mansoni alkaline phosphatase), SmNPP-5 (S. mansoni nucleotide pyrophosphatase-phosphosdiesterase-5) and SmATPDase1 (S. mansoni ATP diphosphohydrolase1).

\section{Figure 2.}

Suppression of schistosome ectoenzyme genes using RNAi.

Relative SmAP (A), Sm NPP-5 (B) and SmATPDase1 (C) gene expression (mean \pm SD, $n=3$ ) in schistosomula treated with SmAP, SmNPP-5, SmATPDase1 (SmATPD), control (grey bar) or no (None) siRNA. One group was treated with siRNAs simultaneously targeting the three ectoenzyme genes (SmAP and SmNPP-5 and SmATPDase1, lane marked "All 3"). In all cases target gene suppression is significantly different from control $(P<0.05)$. D, Western blotting analysis in which protein extracts of parasites treated either with siRNAs simultaneously targeting the three ectoenzyme genes (SmAP and SmNPP-5 and SmATPDase1, lane marked "All 3") or control siRNA or no siRNA (None) are probed with antibody specific for SmAP (top panel), or SmNPP-5 (second panel), or SmATPDase1 (third panel). The bottom panel shows a fragment of the gel stained with Coomassie blue to ensure roughly equal protein loading per lane. The data shown are representative of four independent experiments.

\section{Figure 3.}

Apyrase activity of ecto-enzyme suppressed and control parasites.

Enzyme activity (phosphate $(\mathrm{Pi})$ release per hour, mean $\pm \mathrm{SE}, \mathrm{n}=8$ ) from individual, living adult male schistosomes treated with the indicated siRNAs and incubated with 2mM ATP (A) or ADP (B). In both cases, significantly lower activity is seen in parasites treated with siRNA targeting SmATPDase1 (grey bars) compared to all other groups $(P<0.05)$. The data shown are representative of three independent experiments.

\section{Figure 4.}

Expression of recombinant SmATPDase1.

A. Depiction of the full length 544 amino acid SmATPDase1 protein (top) which contains two transmembrane (TM) domains. Numbers refer to amino acid residues. A truncated version of the protein from residues $\mathrm{S}^{66}$ to $\mathrm{Q}^{507}$, lacking both TM domains, and predicted to be secreted following expression in $\mathrm{CHO}$ cells is depicted below. B. ATPase activity (mean $\pm \mathrm{SE}, \mathrm{n}=3$ ) in CHO-S cell lysates $(10 \mu \mathrm{g} /$ assay) three days after transfection with a full length or secreted or no (None) DNA construct. The inset shows ATPase activity on the surface of living CHO-S cells (75 $\mathrm{x} 10^{3}$ or $150 \times 10^{3}$ ) three days after transfection with a full length or no (control) DNA construct. C. ADPase activity (mean $\pm \mathrm{SE}, \mathrm{n}=3)$ in $\mathrm{CHO}-\mathrm{S}$ cell lysates $(10 \mu \mathrm{g} /$ assay) three days after transfection with a full length or secreted or no (None) DNA construct. The inset shows ADPase activity on the surface of living CHO-S cells $\left(75 \times 10^{3}\right.$ or $\left.150 \times 10^{3}\right)$ three days after transfection with a full length or no (control) DNA construct. In all cases only the activity of the full length construct differs significantly from other groups $(P<0.05)$. The data shown in $\mathrm{B}$ and $\mathrm{C}$ are representative of five independent experiments.

Figure 5.

Characterization of recombinant SmATPDase1. 
726 The top panel (A-C) deals with ATP and the lower panel (D-F) deals with ADP. ATPase activity

727 (A) and ADPase activity (D) in cell lysates (mean \pm SE, $n=3)$ expressing SmATPDase1 (10 $\mu \mathrm{g}$

728 protein) in the presence of added calcium $\left(\mathrm{Ca}^{++}\right)$or magnesium $\left(\mathrm{Mg}^{++}\right)$or nothing (None) or

729 EDTA plus EGTA or $\mathrm{Ca}^{++}$plus thapsigargin $(100 \mu \mathrm{M})$. Michaelis-Menton plot of ATPase activity

730 (B) and ADPase activity (E) in cell lysates expressing rSmATPDase1. The $\mathrm{K}_{\mathrm{m}}$ for ATP is $0.4 \pm$

$7310.02 \mathrm{mM}$ and the $\mathrm{K}_{\mathrm{m}}$ for ADP is $0.252 \pm 0.02 \mathrm{mM}$. The effect of $\mathrm{pH}$ on ATPase activity (C) and

732 ADPase activity $(\mathrm{F})$ in cell lysates expressing SmATPDase1. Data shown are representative of

733 independent experiments performed at least 3 times.

734 Figure 6.

735 The pathway in schistosomes for exogenous ATP catabolism via ADP and AMP to adenosine.

736 Work reported here demonstrates that, of the three ectoenzyme candidates, only SmATPDase1 $(S$.

737 mansoni ATP diphosphohydrolase1) can cleave ATP and ADP. In the final step, SmAP (S.

738 mansoni alkaline phosphatase) can cleave AMP to generate adenosine.

\section{Table 1.}

740 Sequences of oligonucleotides used in qRT-PCR analysis.

741 For each gene a forward $(\mathrm{F})$ and reverse $(\mathrm{R})$ primer were used in conjunction with a FAM dye

742 labeled probe. 


\section{Figure 1}

Ecto-nucleotidase activity in schistosomes.

A, Phosphate (nmol) release (mean $\pm S E, n=8$ ) following the addition of ATP, ADP or AMP $(2 \mathrm{mM})$ to individual live adult male worms over 3 hours. B, Phosphate $(\mathrm{nmol})$ release (mean $\pm \mathrm{SE}, \mathrm{n}=3$ ) following the addition of ATP, ADP or AMP (2mM) to 1,000 schistosomula over 1 hour. In the absence of parasites, no or negligible $(<5 \mathrm{nmol}) \mathrm{Pi}$ is detected. The data shown are representative of at least three independent experiments. C, The proposed pathway in schistosomes for exogenous ATP catabolism via ADP and AMP to adenosine. The following three schistosome tegumental ectoenzymes are hypothesized to be involved: SmAP ( $S$. mansoni alkaline phosphatase), SmNPP-5 (S. mansoni nucleotide pyrophosphatasephosphosdiesterase-5) and SmATPDase1 (S. mansoni ATP diphosphohydrolase1). 


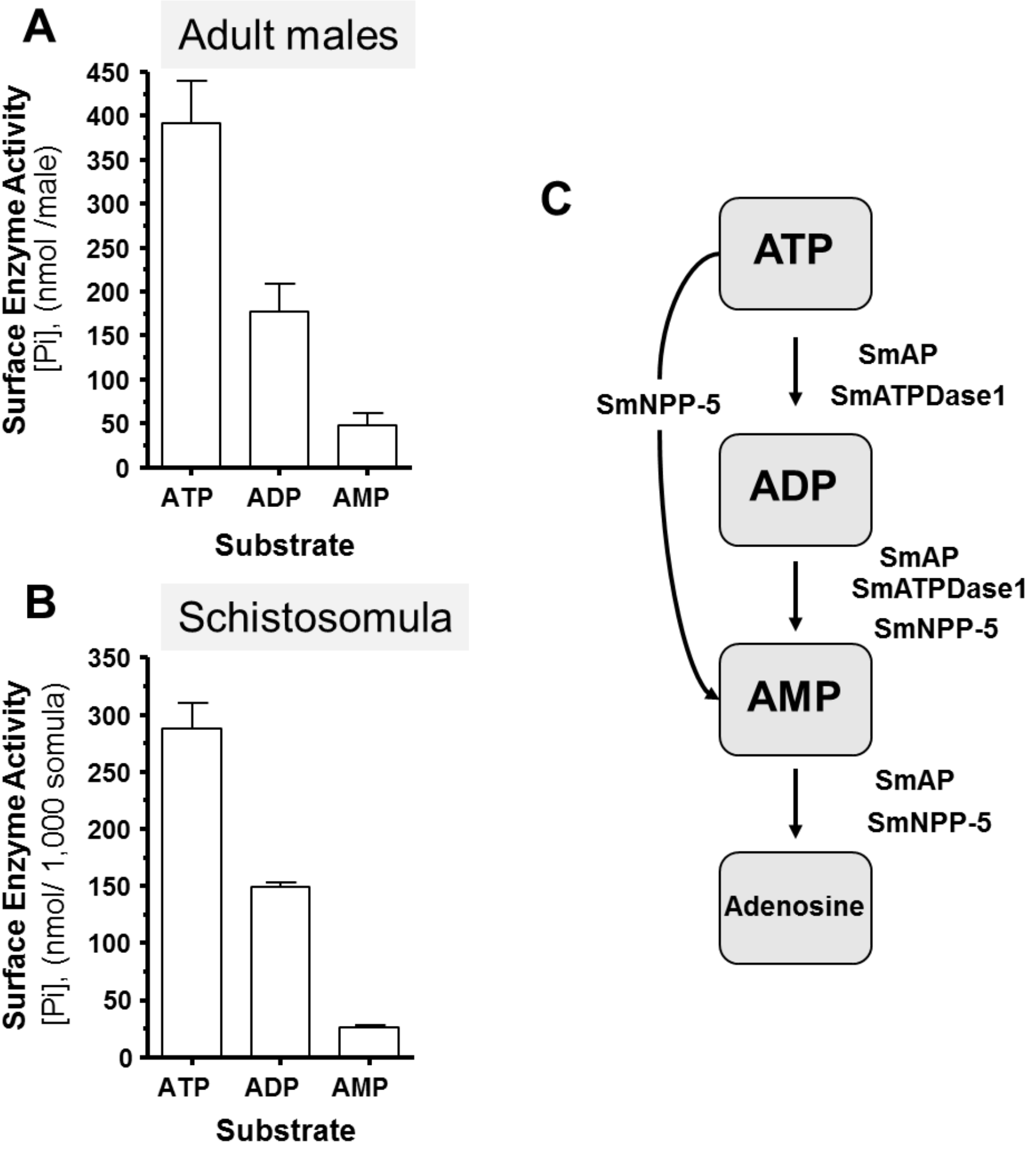




\section{Figure 2}

Suppression of schistosome ectoenzyme genes using RNAi.

Relative SmAP (A), Sm NPP-5 (B) and SmATPDase1 (C) gene expression (mean \pm SD, $n=3$ ) in schistosomula treated with SmAP, SmNPP-5, SmATPDase1 (SmATPD), control (grey bar) or no (None) siRNA. One group was treated with siRNAs simultaneously targeting the three ectoenzyme genes (SmAP and SmNPP-5 and SmATPDase1, lane marked "All 3"). In all cases target gene suppression is significantly different from control $(P<0.05)$. D, Western blotting analysis in which protein extracts of parasites treated either with siRNAs simultaneously targeting the three ectoenzyme genes (SmAP and SmNPP-5 and SmATPDase1, lane marked "All 3") or control siRNA or no siRNA (None) are probed with antibody specific for SmAP (top panel), or SmNPP-5 (second panel), or SmATPDase1 (third panel). The bottom panel shows a fragment of the gel stained with Coomassie blue to ensure roughly equal protein loading per lane. The data shown are representative of four independent experiments. 
A
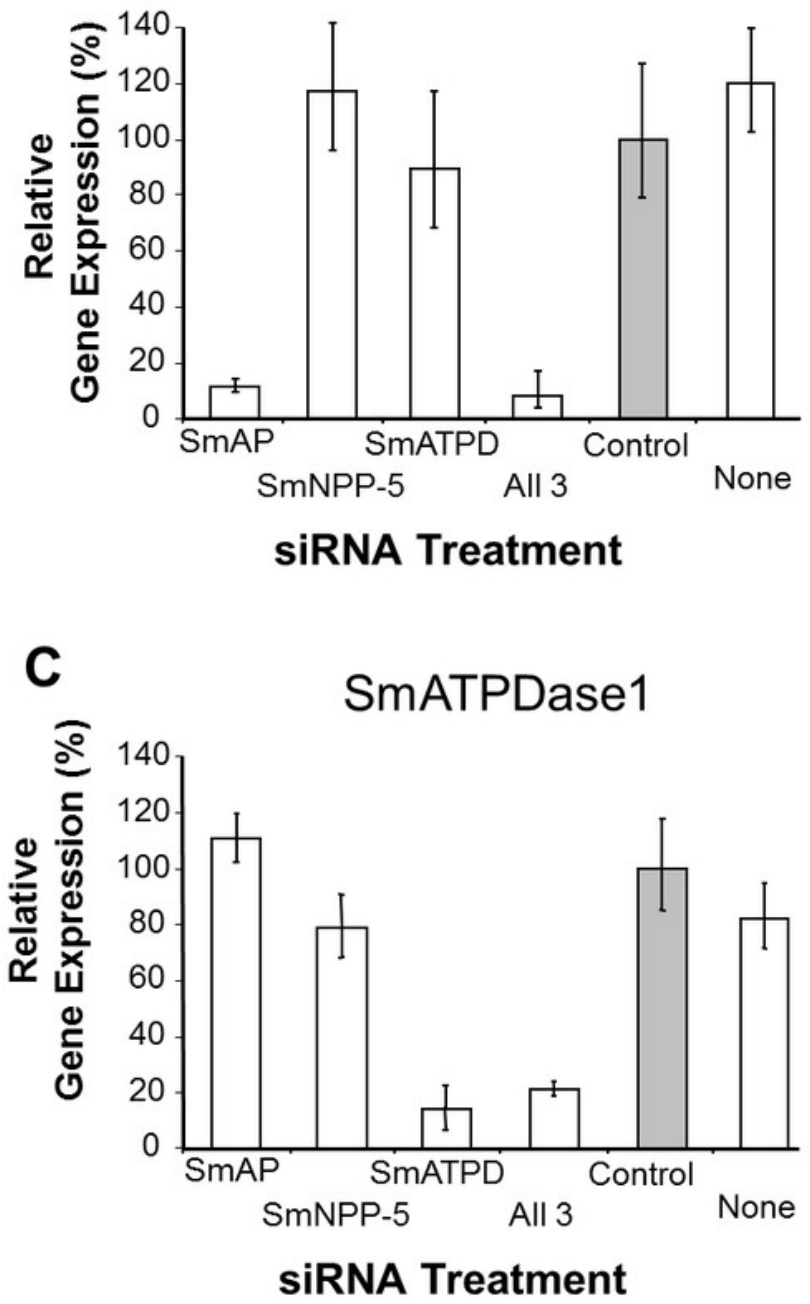

B

SmNPP-5

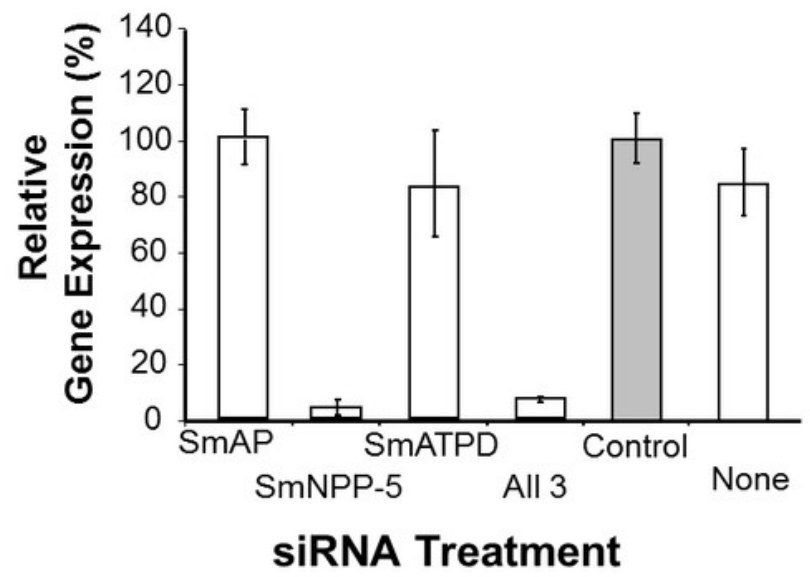

D

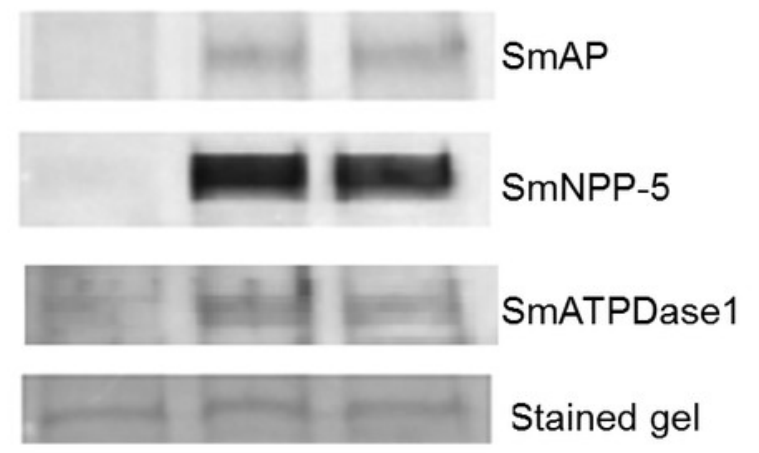

All 3 Control None siRNA Treatment 


\section{Figure 3}

Apyrase activity of ecto-enzyme suppressed and control parasites.

Enzyme activity (phosphate $(\mathrm{Pi})$ release per hour, mean $\pm \mathrm{SE}, \mathrm{n}=8$ ) from individual, living adult male schistosomes treated with the indicated siRNAs and incubated with 2mM ATP (A) or ADP (B). In both cases, significantly lower activity is seen in parasites treated with siRNA targeting SmATPDase1 (grey bars) compared to all other groups $(P<0.05)$. The data shown are representative of three independent experiments.
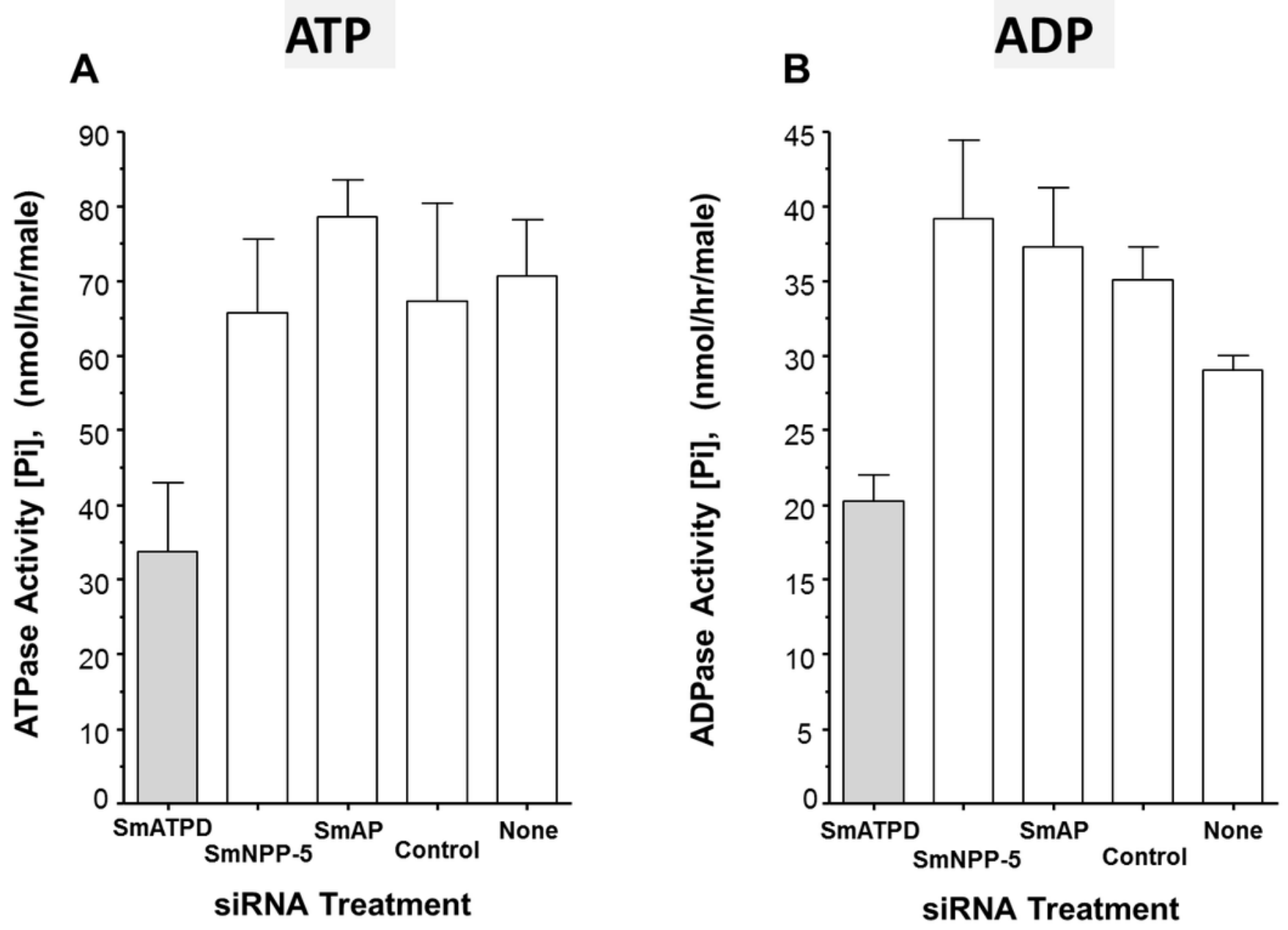


\section{Figure 4}

Expression of recombinant SmATPDase1.

A. Depiction of the full length 544 amino acid SmATPDase1 protein (top) which contains two transmembrane (TM) domains. Numbers refer to amino acid residues. A truncated version of the protein from residues $S^{66}$ to $Q^{507}$, lacking both TM domains, and predicted to be secreted following expression in $\mathrm{CHO}$ cells is depicted below. B. ATPase activity (mean $\pm \mathrm{SE}, \mathrm{n}=3$ ) in CHO-S cell lysates (10 $\mathrm{g} /$ assay) three days after transfection with a full length or secreted or no (None) DNA construct. The inset shows ATPase activity on the surface of living CHO-S cells $\left(75 \times 10^{3}\right.$ or $\left.150 \times 10^{3}\right)$ three days after transfection with a full length or no (control) DNA construct. C. ADPase activity (mean $\pm \mathrm{SE}, \mathrm{n}=3$ ) in CHO-S cell lysates (10 $\mu \mathrm{g} /$ assay) three days after transfection with a full length or secreted or no (None) DNA construct. The inset shows ADPase activity on the surface of living CHO-S cells $\left(75 \times 10^{3}\right.$ or $\left.150 \times 10^{3}\right)$ three days after transfection with a full length or no (control) DNA construct. In all cases only the activity of the full length construct differs significantly from other groups $(P<0.05)$. The data shown in $B$ and $C$ are representative of five independent experiments. 
A SmATPDase1

Full length

SmATPDase1

Secreted

\section{6 \\ $\downarrow$ \\ TM}

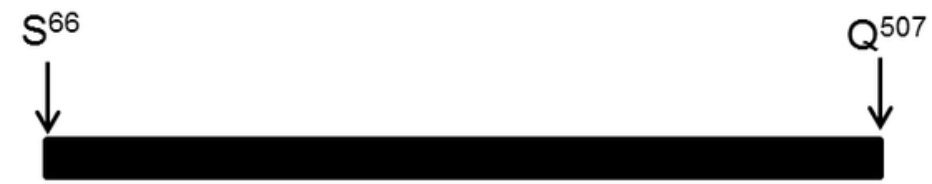

ATP

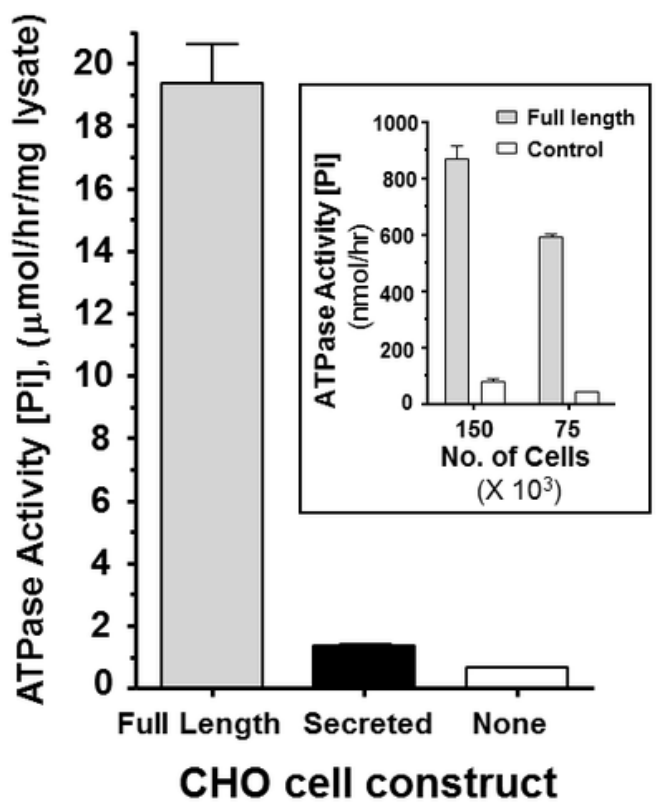

C ADP

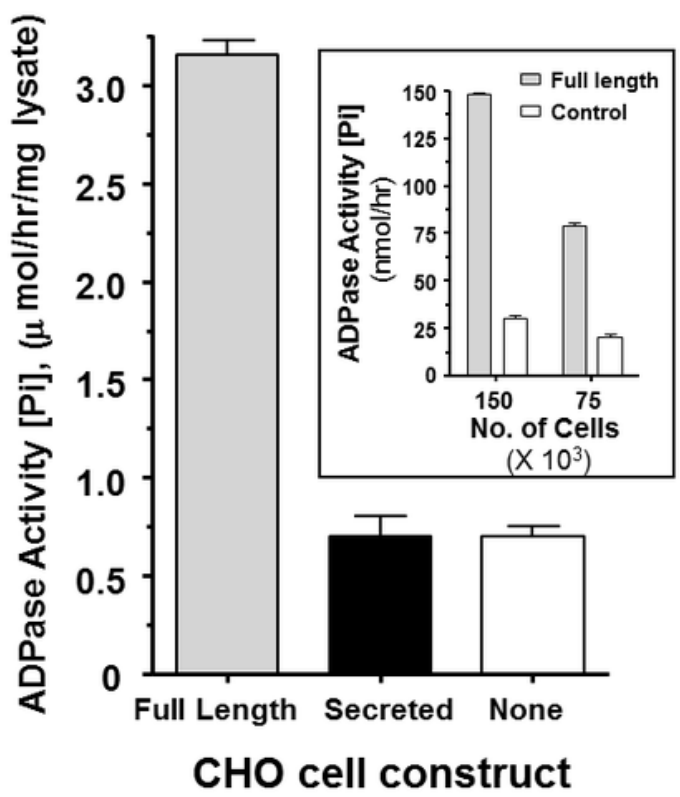




\section{Figure 5}

Characterization of recombinant SmATPDase1.

The top panel (A-C) deals with ATP and the lower panel (D-F) deals with ADP. ATPase activity $(A)$ and ADPase activity (D) in cell lysates (mean $\pm S E, n=3$ ) expressing SmATPDase1 (10 $\mu \mathrm{g}$ protein) in the presence of added calcium $\left(\mathrm{Ca}^{++}\right)$or magnesium $\left(\mathrm{Mg}^{++}\right)$ or nothing (None) or EDTA plus EGTA or $\mathrm{Ca}^{++}$plus thapsigargin $(100 \mu \mathrm{M})$. Michaelis-Menton plot of ATPase activity (B) and ADPase activity (E) in cell lysates expressing rSmATPDase1. The $K_{m}$ for ATP is $0.4 \pm 0.02 \mathrm{mM}$ and the $K_{m}$ for ADP is $0.252 \pm 0.02 \mathrm{mM}$. The effect of pH on ATPase activity (C) and ADPase activity (F) in cell lysates expressing SmATPDase1. Data shown are representative of independent experiments performed at least 3 times.
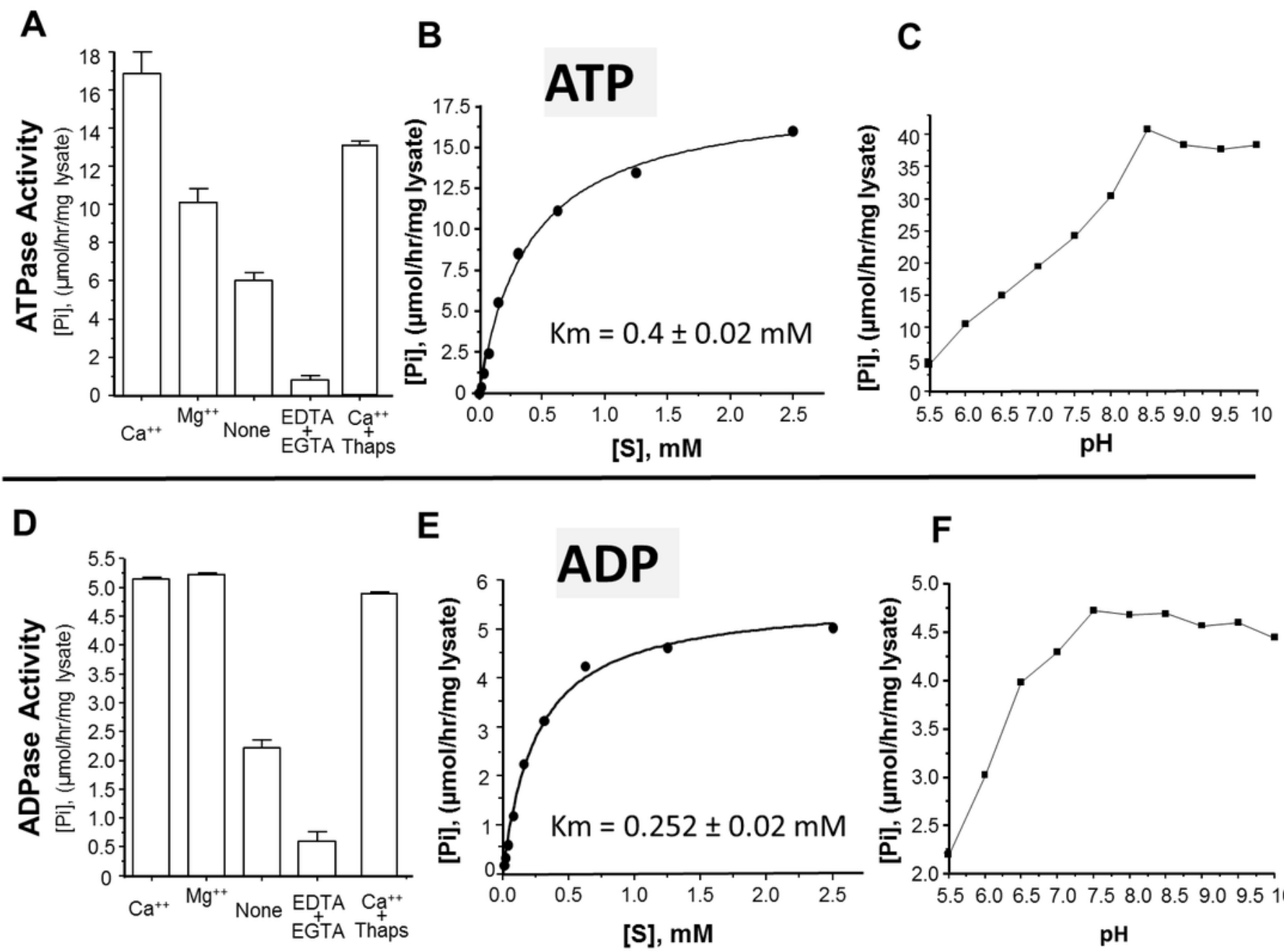

E
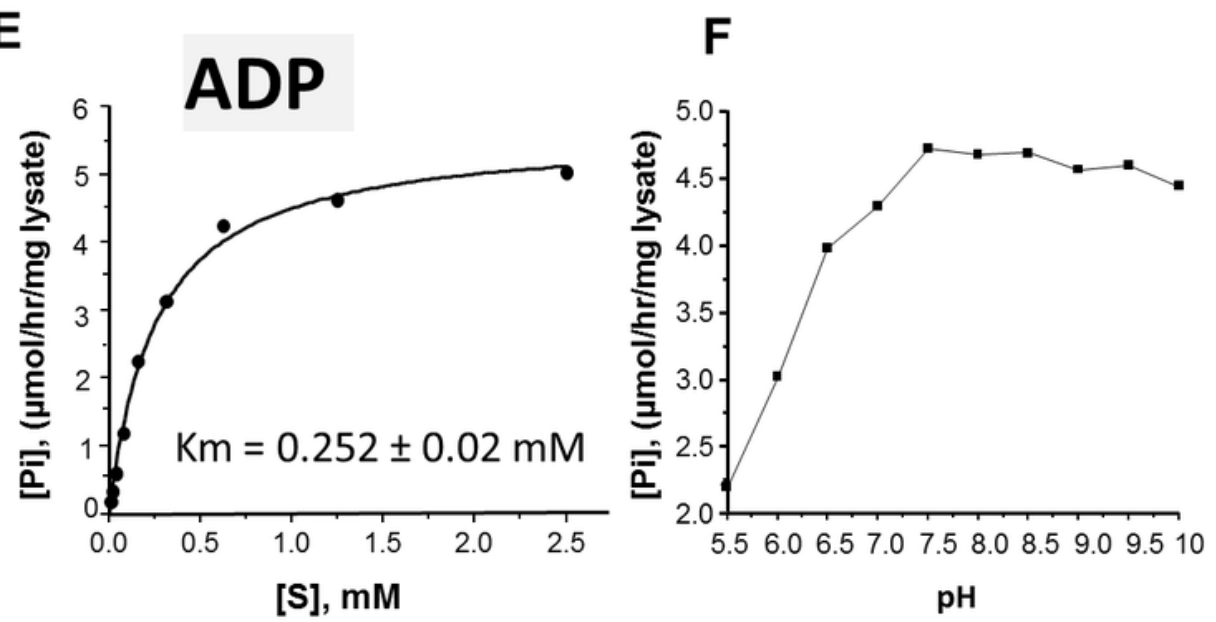


\section{Figure 6}

The pathway in schistosomes for exogenous ATP catabolism via ADP and AMP to adenosine.

Work reported here demonstrates that, of the three ectoenzyme candidates, only

SmATPDase1 (S. mansoni ATP diphosphohydrolase1) can cleave ATP and ADP. In the final step, SmAP (S. mansoni alkaline phosphatase) can cleave AMP to generate adenosine.

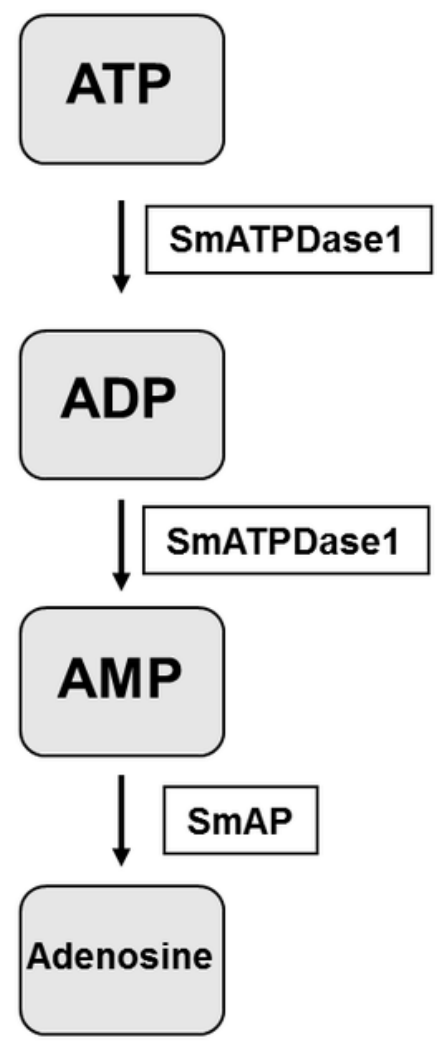




\section{Table 1 (on next page)}

Sequences of oligonucleotides used in qRT-PCR analysis.

For each gene a forward $(F)$ and reverse $(R)$ primer were used in conjunction with a FAM dye labeled probe. 


\begin{tabular}{|c|c|c|}
\hline Gene & Primer name & Sequence \\
\hline \multirow[t]{4}{*}{ SmAP } & SmAP-F & 5'-GCCATCCGACAAGGAATATAAGTGT -3' \\
\hline & Sm-AP-R & 5'-GGTCCATTGAAAAAGGAGGATATGAGA -3' \\
\hline & $\tilde{\sigma}$ & \\
\hline & $\begin{array}{c}\text { Sm-tine-FAM } \\
\frac{1}{7}\end{array}$ & 5'-FAM- ATCTCCTTTTGCAGTATTATC - -3' \\
\hline \multirow[t]{3}{*}{ SmNPP-5 } & $\sum_{\sigma}^{\operatorname{Sm} \mathbb{N P} P-5-F}$ & 5'-GGACGATTATTGCTGACAGAACGT -3' \\
\hline & Smitisp-5-R & 5'-TGGAGACATCTCTTTGTAATCTGGATCA -3' \\
\hline & SmAP-FAM & 5'-FAM-TTTATTTTTCAGGGTTATCCC -3' \\
\hline \multirow[t]{3}{*}{ SmATPDase1 } & Sn बTPd-F & 5'-CTGATGCCGTTATGAAGTTTTGCA -3' \\
\hline & $\mathrm{S}-\mathrm{ATPd}-\mathrm{R}$ & 5'-ACCTTCAGCAAGTGCATGTTGA-3' \\
\hline & SmATPd-FAM & 5'-FAM- AAAGATGTGGCTAAAATT -3' \\
\hline \multirow[t]{3}{*}{$\alpha$-Tubulin } & Tub-F & 5'-GGTTGACAACGAGGCCATTTATG-3' \\
\hline & Tub-R & 5'-GCAGTAAACCCTTGGTCAGATAATTTTG -3' \\
\hline & Tub-Probe & 5'-FAM-ATATTTGTCGACGGAAT-3' \\
\hline
\end{tabular}

